\title{
A teoria hegeliana da imaginação
}

Héctor Ferreiro*

DOI 10.20399/P1982-999X.2016v1n1pp139-154

Resumo: No processo do conhecimento a imaginação desempenha para Hegel o estágio no qual a mente humana dissocia o objeto em dois diferentes conteúdos, o conteúdo-coisa do mundo externo e o conteúdo interno da própria mente, de tal modo que ambas as versões do mesmo devem corroborar-se mutuamemente ao modo de uma síntese simples de elementos heterogéneos que apenas em seu cotejamento reconhecem sua identidade. Na atividade de compreensão, ao contrário, este dualismo é suprassumido e, com ele, o empirismo e a teoria correspondista da verdade que, aos olhos de Hegel, está em sua base.

Palavras-Chave: Teoria do Conhecimento, teoria da imaginação, teoria correspondista da verdade, idealismo e filosofía analítica.

Abstract: In the process of knowledge imagination is, according to Hegel, the point where the humanmind dissociates the object into two different contents - i.e. the thing of the external world and theinternal content of the mind -, so that both versions of the object must corroborate each other in theway of a synthesis of heterogenous elements that only in their collation recognizes their identity. Comprehension sublates this dualism, and, by doing that, it sublates also the empiricist approach to knowledge and the correspondence theory of truth which, for Hegel, are at its basis.

Keywords: Hegel - Epistemology - Theory of Imagination - Correspondence Theory of Truth Idealism and Analytic Philosophy

\section{A concepção do objeto enquanto unidade de sensibilidade e inteligibilidade}

Tanto na filosofia antiga como na Medieval atribuíram à faculdade da imaginação, antes de tudo, duas funções, a saber: a reprodução das imagens sensíveis e a síntese do sensível e do inteligível ${ }^{1}$. Neste contexto, a Filosofia Antiga e a Medieval

\footnotetext{
* Pontificia Universidad Católica Argentina, Consejo Nacional de Investigaciones Científicas y Técnicas Buenos Aires, Argentina, email: hferreiro@ conicet.gov.ar. Uma primeira versão deste texto foi publicada em Revista de Estudios Hegelianos, PUC/CHILE, Valparaíso, 2012. Tradução de Danilo Vaz-Curado R. M. Costa (UNICAP).

${ }^{1}$ Cf. Watson, G. (1988). Phantasia in Classical Thought, Galway: Galway University Press; Bundy, M. W. (1928). The Theory of Imagination in Classical and Medieval Thought, Urbana: University of Illinois Press. Sobre la teoría de la imaginación en Aristóteles en particular, véase: Wedin, M. (1988). Mind and Imagination in Aristotle, New Haven: Yale University Press; Watson, G. (1982). Phantasia in Aristotle: De Anima 3.3., Classical Quarterly, 32, 101-113; White, K. (1985). The Meaning of Phantasia in Aristotle's De Anima, III, 3-8, Dialogue, 24, 483-505; Rees, D. (1971). Aristotle's Treatment of Phantasia. En Anton, J., Kustas, G. (Eds.), Essays in Ancient Greek Philosophy (pp. 491-504). Albany: State University of New York Press; Labarrière, J.-L. (1984). Imagination humaine et imagination animale chez Aristote. Phronesis, 29, 17-49; Engmann, J. (1976). Imagination and Truth in Aristotle. Journal of the History of Philosophy, 14 (3), 259-265; Schofield, M. (1978). Aristotle on the Imagination. En Lloyd, G., Owen, G. (Eds.), Aristotle on Mind and the Senses (pp. 99-141). Cambridge: Cambridge University Press; Modrak, D. (1986). Phantasia reconsidered. Archiv für Geschichte der Philosophie, 68, 47-69.
} 
tendeu a identificar o conteúdo da imagem com o objeto singular da sensação e a diferenciá-lo assim especificamente do conteúdo do conceito abstrato, que assinalava então o começo do reino do inteligível. Segundo esta perspectiva, a imaginação reproduzia no âmbito interno da subjetividade o mesmo objeto singular antes percebido como uma coisa do mundo externo; a partir deste conteúdo singular interior, o sujeito abstraia por sua vez o conceito universal e retornava de imediato a ele para reconfirmar seu conceito - a teoria do conhecimento da Escolástica medieval designou a este último ato "conversio ad phantasmata". ${ }^{2}$ A partir da Idade Moderna, esta função mediadora e sintética da imaginação começou a cobrar preeminência sobre sua função meramente reprodutora. Assim, na filosofia de Descartes a imaginação assinala o ponto de encontro entre a alma e o corpo, entre a res cogitans e a res extensa. ${ }^{3} \mathrm{Na}$ filosofia de Kant, por sua vez, a dualidade da res extensa e res cogitans persiste e se deixa entrever na dissociação ente a receptividade e espontaneidade. Em feito, na concepção kantiana do conhecimento a dualidade substancial da mente e do mundo reaparece transfigurada sob a figura da síntese do sujeito cognoscente que re-aciona a realidade em si que atua sobre ele: a função primaria do esquematismo da imaginação é para Kant, precisamente, vincular a esfera fundamentalmente receptiva do sensível com a esfera espontânea do inteligível. ${ }^{4}$ Remetendo ao espírito da filosofia cartesiana contida na tese do Cogito, na qual vê um princípio essencialmente diferente do da filosofia de Kant, Hegel critica e abandona a dualidade de receptividade e espontaneidade e com isso, ulteriormente, a dualidade entre sensibilidade e inteligibilidade. ${ }^{5}$ O conteúdo sensível não é para Hegel

\footnotetext{
${ }^{2}$ Cf. por exemplo, Tomás de Aquino, Summa Theologiae II-II, q. 175 a. 5 co.; I, q. 89 a. 1 co.; I, q. 89 a. 5 co.; I, q. 89 a. 6 co.; I, q. 88 a. 1 co. Cf. Igualmente,Summa Theologiae I, q. 94 a. 2 co.; I, q. 84 a. 7 ; I, q. 85 a. 1 ad 2 y ad 5; Super Sent., lib. 4 d. 50 q. 1 a. 2 co.; Super Sent., lib. 4 d. 50 q. 1 a. 2 ad 1.; Super Sent., lib. 4 d. 50 q. 1 a. 2 ad 6. Para o problema geral da imaginação na filosofiada Idade Média, ver, Bundy, M. W., op. cit.; Kemp, S. (1996). Cognitive Psychology in the Middle Ages. Westport: Greenwood Press; Kemp, S., Fletcher, G. (1993). The Medieval Theory of the Inner Senses, American Journal of Psychology, 106, 559-576.

${ }^{3}$ Cf. Ferrarin, A. (1995). Kant's Productive Imagination And Its Alleged Antecedents, Graduate Faculty Philosophy Journal, 18 (1), 65-92, especialmente 78-82. Para uma análise geral da teoria da imaginação em Descartes, veja-se Marion, J.-L. (1975). Sur l'ontologie grise de Descartes. Paris: Vrin, 122ss.; Lachterman, D. (1989). The Ethics of Geometry: A Genealogy of Modernity. New York: Routledge, especialmente 195-205.

${ }^{4}$ Para uma análise da teoriada imaginação em Kant, veja-se: Banham, G. (2005). Kant's Transcendental Imagination. New York: Palgrave Macmillan; Freydberg, B. (2005). Imagination in Kant's Critique of Practical Reason. Bloomington and Indianapolis: Indiana University Press; Makkreel, R. (1990). Imagination and Interpretation in Kant. Chicago: The University of Chicago Press. Cf. também Ferrarin, A. (1995). Construction and Mathematical Schematism: Kant on the Exhibition of a Concept in Intuition. Kant-Studien, 86 (2), 1-47.

${ }^{5}$ Veja-se a este respeito Ferreiro, H. (2012). La interpretación hegeliana del Cogito. En Lorenzo, L., Paul, A. (Eds.), Perspectivas de investigación en Filosofía: Aporías de la razón moderna (pp. 41-52). Los Polvorines-Buenos Aires: Ediciones de la Universidad Nacional de General Sarmiento.
} 
menos ideal e espontâneo que o conteúdo inteligível. A racionalidade humana é a substância única fora da qual não há absolutamente nada que possa atuar sobre ela. Isto significa mais claramente: os objetos não são em verdade coisas que causem o conhecimento de si mesmo em uma subjetividade concebida correlativamente com uma coisa que os reflita ou os represente; a subjetividade é, em rigor, o espaço lógico no qual se constitui idealmente um sistema de objetos ao qual se lhe atribui realidade. Este novo princípio, que na opinião de Hegel haveria sido colocada pela primeira vez na forma clara por Descartes ${ }^{6}$, modifica radicalmente a concepção anterior sobre o fenômeno do conhecimento e, sobre essa base, a concepção sobre a sensibilidade, a inteligibilidade e suas relações mútuas. A atividade cognitiva consiste para Hegel em suprassumir a aparência de substancialidade que tem o objeto sensível a respeito do sujeito que o conhece $^{7}$. Esta suprassunção é em seu reverso a suprassunção de toda variante de concepção receptiva e causal do conhecimento. O tratamento que Hegel faz da imagem e da imaginação se inscreve nesta recolocação geral do fenômeno do conhecimento como atividade do desvelamento da consubstancialidade do objeto com a razão humana que o conhece.

Deste modo, ressemantizada dentro destas margens precisas, também na teoria do conhecimento de Hegel a imaginação ocupa uma posição intermediária entre a intuição sensível do objeto e sua compreensão o elemento ideal da linguagem: neste novo

\footnotetext{
${ }^{6}$ Cf. Hegel, G. W. F., Vorlesungen über die Geschichte der Philosophie (Hegel: Werke 20.) Frankfurt am Main: Surkamp Verlag, 1970, 120: Wir kommen eigentlich jetzt erst zur Philosophie der neuen Welt und fangen diese mit Cartesius an. Mit ihm treten wir eigentlich in eine selbständige Philosophie ein, welche weiß, daß sie selbständig aus der Vernunft kommt und daß das Selbstbewußtsein wesentliches Moment des Wahren ist. Ibid., 130: Hiermit ist auf einmal die Philosophie in ein ganz anderes Feld, ganz anderen Standpunkt versetzt, nämlich in die Sphäre der Subjektivität, das Gewisse. (...) Cartesius fängt also mit dem Standpunkt des Ich als des schlechthin Gewissen an, wie auch Fichte anfängt; ich weiß, es stellt sich in mir dar. Ein ganz anderer Boden ist so fürs Philosophieren gegeben. Ibid., 136: Es sind verschiedene Bestimmungen, Denken und Sein, - und nur ihre Verschiedenheit muß aufgezeigt werden; daß sie identisch sind, diesen Beweis hat Descartes nicht geführt. Es steht einstweilen voran, es ist die interessanteste Idee der neueren Zeit überhaupt; er [= Descartes] hat sie zuerst aufgestellt. Cf. também Ibid., 123: René Descartes ist in der Tat der wahrhafte Anfänger der modernen Philosophie, insofern sie das Denken zum Prinzip macht. Ibíd., 70: Mit Cartesius fängt eigentlich die Philosophie der neueren Zeit, das abstrakte Denken erst an.

${ }^{7}$ Cf. Hegel, G. W. F., Enzyklopädie der philosophischen Wissenschaften im Grundrisse (Hegel: Werke 810). Frankfurt am Main: Surkamp Verlag, 1970, §§ 441-443 [adiante: Enz]; mais precisamente Enz § 442Z: Die Existenz des Geistes, das Wissen, ist die absolute Form, $d$. h. die den Inhalt in sich selber habende Form, oder der als Begriff existierende, seine Realität sich selber gebende Begriff. Daß der Inhalt oder Gegenstand dem Wissen ein gegebener, ein von außen an dasselbe kommender sei, ist daher nur ein Schein, durch dessen Aufhebung der Geist sich als das erweist, was er an sich ist,- nämlich das absolute Sichselbstbestimmen, die unendliche Negativität des ihm und sich selber Äußerlichen, das alle Realität aus sich hervorbringende Ideelle. Das Fortschreiten des Geistes hat folglich nur den Sinn, daß jener Schein aufgehoben werde, daß das Wissen sich als die allen Inhalt aus sich entwicklende Form bewähre.
} 
contexto, sem dúvida sensibilidade e inteligibilidade não devem ser entendidas nem na linha da filosofia antiga e medieval como as esferas respectivas do material e do imaterial, nem na linha da filosofia kantiana como as do receptivo e do espontâneo. ${ }^{8} \mathrm{Na}$ filosofia de Hegel, todo conteúdo resulta no final em haver sido sempre ideal; o processo cognitivo do qual a imaginação é apenas um momento é precisamente o processo de explicitação dessa exaustiva idealidade originária de toda determinação cognoscível.

Até o sistema de idealismo absoluto com sua tese fundacional da identidade do objeto e do sujeito, o conteúdo sensível foi em essência concebido ora como a coisa mesma real do mundo externo - e correlativamente, o conteúdo inteligível ou conceitual como a presença ideal das formas em si mesmas imateriais do unierso (tal é o caso de Aristóteles) -ora como o resultado imanente da própria atividade espontânea do entendimento humano (este é o caso por exemplo, de Kant). Hegel, ao contrário, abandona esta dualidade tradicional da teoria do conhecimento e a substitui por uma teoria de três fases - intuição, representação, pensar - sobre a base de sua concepção lógica da singularidade, a universalidade abstrata e a universalidade concreta. Neste contexto, a sensibilidade ou empiricidade do conteúdo não está relacionada nem com a materialidade nem com a receptividade, assim como correlativamente a inteligibilidade tampouco está com a imaterialidade e a espontaneidade. A sensibilidade está para Hegel primariamente correlacionada com a singularidade concreta, por sua vez, a inteligibilidade é, em geral, a contraface da universalidade, a saber, mais claramente, da capacidade de um conteúdo de assumir determinações diferentes sob si sem perder com isso sua identidade consigo mesmo. Sem dúvida, para Hegel, o sensível não exclui forçosamente ao universal - nem vice-versa. Com efeito, o objeto de uma intuição intelectulizada desde uma teoria é, por exemplo, um conteúdo sensível, porém precisamente enquanto mediado consigo mesmo desde conteúdos conceituais é também

\footnotetext{
${ }^{8}$ Cf. especialmente Enz $\S \S 455-460$; Hegel, G. W. F., Vorlesungen über die Philosophie des Geistes. Berlin 1827/1828. Nachgeschrieben von J E. Erdmann und F. Walter, Hamburg: Meiner, 1994, 202-213 [adiante: VPhG]. Sobre a teoría hegeliana da imaginação, veja-se: Bates, J. A. (2004). Hegel's Theory of Imagination. Albany: State University of New York Press; Düsing, K. (1991). Hegels Theorie der Einbildungskraft. En Hespe, F., Tuschling, B. (Eds.), Psychologie und Anthropologie oder Philosophie des Geistes. Beiträge zu einer Hegel-Tagung in Marburg 1989 (pp. 297-320). Stuttgart-Bad Canstatt: Frommann-Holzboog; Sallis, J. (1987). Imagination and Presentation in Hegel's Philosphy of Spirit. En Stillman, P. (Ed.), Hegel's Philosophy of Spirit (pp. 66-88). Albany: State University of New York Press; Sallis, J. (1987). Spacings - of Reason and Imagination in Texts of Kant, Fichte, Hegel. Chicago/London: The University of Chicago Press; Verene, D. (1982). La imaginación en Hegel. Revista de Filosofía, 20, 23-35.
} 
um conteúdo universal. ${ }^{9}$ Somente o universal abstrato, que é para Hegel o âmbito específico da forma cognitiva da representação e, dentro desta, mais precisamente, do da imaginação, pareceria excluir a sensibilidade. Não obstante, desde as premissas de sua teoria lógica sobre a universalidade, a particularidade e a singularidade, sensibilidade e inteligibilidade não se excluem segundo Hegel, como dois âmbitos especificamente diferentes e refratários: sensibilidade e inteligibilidade são formas de cada conteúdo conhecido: o que as reúne e supera numa unidade não é a imaginação como um terceiro elemento, como um termo médio de onde elas se vinculam então sinteticamente, senão o conteúdo enquanto compreendido, a respeito de cuja necessidade intrínseca sensibilidade e inteligibilidade, singularidade e universalidade tornam-se tao somente formas ou momentos. A atividade cognitiva que Hegel denomina pensar ou compreender (Begreifen) ${ }^{10}$ não é senão a teoria geral do mundo, o sistema dos objetos - o conceito (Begriff) - dentro do qual existe o real como um unidade coerente de aspectos sensíveis e não sensíveis. No interior da teoria na qual se compreende a realidade restam, pois completamente intermediadas e superadas em sua separação e diferença abstrata - em sua particularidade (Besonderheit) - a singularidade e a universalidade, a sensibilidade e a inteligibilidade.

\section{Os atos da imaginação}

Em todas as formas da rememoração (Erinnerung), isto é, na imagem inconsciente, a imagem fugaz e transitória e a imagem que o sujeito reconcientiza ou recorda ao intuir o mesmo objeto dessa imagem, ${ }^{11}$ o conteúdo ou determinidade com o que o sujeito se determina a si mesmo em si mesmo não aparece ainda como sua própria determinação, como sua autodeterminação. $\mathrm{Na}$ forma da imaginação, pelo contrário, a autodeterminação do sujeito existe enquanto tal, a saber, aparece como uma determinação em si mesma subjetiva: em efeito, quem se representa a imagem de um objeto real em seu interior sabe que essa imagem não é a coisa exterior mesma, senão tão somente uma imagem subjetiva dela. A imagem existe então como um conteúdo que subsiste na interioridade ideal do sujeito e, reciprocamente, o sujeito torna-se sujeito

\footnotetext{
9 Cf. neste sentido Enz $\S$ 449Z: Die vollendete Erkenntnis gehört nur dem reinen Denken der begreifenden Vernunft an, und nur derjenige, welcher sich zu diesem Denken erhoben hat, besitzt eine vollkommen bestimmte wahrhafte Anschauung - bei ihm bildet die Anschauung bloß die gediegene Form, in welche seine vollständig entwickelte Erkenntnis sich wieder zusammendrängt.

${ }^{10} \mathrm{Cf}$. VPhG, 228; Enz $\$ 467$.

${ }^{11}$ Cf., respectivamente, Enz $§ 452, \S 453$ y $\$ 454$.
} 
explícito na imagem. A imaginação que reproduz uma imagem assinala com isto o começo do re-presentar em sentido próprio.

A concreção das diferentes determinações que definem um objeto - concreção que na forma a intuição o sujeito encontra ou, em outros termos, que lhe é ada - se converte na forma da imagem no resultado de sua sujeição e coesão ativa por parte do sujeito. Quando no trânsito a forma da representação em geral reduz o conteúdo intuído a uma determinação de si mesma ou autodeterminação, a mente humana torna-se sujeito atual desse conteúdo: agora é propriamente ela que sustenta e suporta a concreção do objeto e regula ativamente o grau de conexão ou de inconexão de suas diferentes determinações. Assim, quando a mente reproduz a imagem do intuído em seu interior, a co-presença das determinações que constituíam o contexto espaço-temoral do conteúdo dessa imagem na forma prévia da intuição é agora, a rigor, uma relação com esse grupo de determinações delimitado como conteúdo imaginado, relação que é operada pela mente enquanto sujeito de ambos grupos de determinações. ${ }^{12}$

Em efeito, neste plano todas as determinações do mundo exterior intuído, a saber, tanto as do conteúdo que a mente decide delimitar como uma imagem como as do conjunto mais amplo que constituía o contexto espaço-temporal originário desse conteúdo, permanecem reduzidas a determinações ativamente em relação entre si. Mais claramente: quando o sujeito reproduz em seu interior um conteúdo que intuiu num determinado contexto exterior neste mesmo contexto e não em outro - por exemplo, quando se imagina um objeto ao lado dos mesmos objetos que lhe rodeavam na intuição exterior - também as determinações que constituem esse contexto são propriamente falando imagens que são reproduzidas em forma contígua as que fazem do conteúdo da imagem aproximadamente o mesmo conteúdo que o que antes foi intuído. Porém inclusive as diferentes determinações que delimitam o conteúdo específico de uma imagem são cada uma delas também imagens que a mente mantém conectadas conformando esse conteúdo ainda concreto e sensível. A mente humana tem justamente por isso a capacidade de desagregar desde si mesma a coesão de dito conteúdo e de separar e destacar alguma ou algumas das determinações que, em sua unidade

12 Cf. neste sentido Enz $\S$ 455: Die nächste Beziehung der Bilder ist die ihres mit aufbewahrten äußerlichen unmittelbaren Raums und Zeit. VPhG, 203: Die nächste Weise der Beziehung ist, daß von mir nebeneinander reproduziert wird, was im Raum neben-oder in der Zeit nacheinander erfolgte. Wenn etwas auch keinen objektiven Zusammenhang hat als bloß nach der Zeit, fehlt beim Reproduzieren auch das Andere nicht. Das ist ein Assoziieren, bei dem sich die Einbildungskraft mehr daran hält, wie dieser Inhalt schon verbunden sich findet. 
constituem o conteúdo da imagem. Esta desagregação da concreção que tem, todavia, o conteúdo de toda a imagem define na teoria de Hegel a abstração (Abstraktion). ${ }^{13} \mathrm{O}$ caráter sensível do conteúdo da imagem resulta para Hegel de sua remanescente espaçotemporalidade; a abstração é justamente a atividade de decompor neste contexto espaçotemporal que persiste no interior do sujeito como espaço-temporal subjetiva. ${ }^{14}$

O conteúdo da imagem contém menos determinações que o conteúdo que foi intuído como um objeto exterior ao sujeito. A quantidade de determinações que o conteúdo da imagem não possui a respeito do objeto intuído e variável. Nossa imagem de um objeto contém uma quantidade limitada; esta quantidade é sempre menor que a que constitui como tal o objeto da intuição e podem de fato variar em cada nova reprodução da imagem. A ativa negação por parte da mente da exaustiva concreção que tem todo conteúdo na forma da intuição se incrementa gradualmente no processo que vai da forma da intuição à da imaginação reprodutiva. Hegel não esclarece expressamente em que grau exato de negatividade e separação de um conteúdo com respeito de seu contexto inicialmente exaustivo e saturado na intuição se produz a passagem da imagem à representação abstrata; ${ }^{15}$ esta ambiguidade entre a imagem e a representação - ou conceito abstrato - é justamente a tese mais relevante de Hegel a este respeito: ela significa mais precisamente que a diferença entre imagem sensível e conceito abstrato é para Hegel fluida e por isso mesmo, trivial. A sensibilidade de um conteúdo vem dada por sua concreção, isto é, por sua presença num plexo de determinações, quanto menor a concreção, menos sensível será o conteúdo. Deste modo, aos olhos de Hegel a sensibilidade é, a rigor, uma forma meramente extrínseca de cada determinação conhecida.

Assim quando na fantasia (Phantasie), segunda forma geral da imaginação, o sujeito converte o conteúdo variavelmente concreto e sensível da imagem e o conceito abstrato no significado (Bedeutung) de um símbolo ou de um signo permanecem

\footnotetext{
${ }^{13}$ Cf. Enz $\S 455 \mathrm{~A}$.

${ }^{14}$ Cf. Enz § 456Z: Schon die Bilder sind allgemeiner als die Anschauungen; sie haben indes noch einen sinnlich-konkreten Inhalt, dessen Beziehung auf anderen solchen Inhalt ich bin. (...) Dies Gemeinsame ist entweder irgendeine in der Form der Allgemeinheit erhobene besondere Seite des Gegenstandes, wie z.B. an der Rose die rote Farbe, oder das konkret Allgemeine, die Gattung, z.B. an der Rose die Pflanze, - in jedem Falle aber eine Vorstellung, die durch die von der Intelligenz ausgehende Auflösung des empirischen Zusammenhangs der mannigfaltigen Bestimmungen des Gegenstandes zustandekommt. (...) Allerdings ist das dem Bilde angehörende Besondere ein Gegebenes, die Zerlegung der konkreten Einzelheit des Bildes und die dadurch entstehende Form der Allgemeinheit kommt aber, wie bemerkt, von mir her.

${ }^{15} \mathrm{Cf}$. Enz $\S 455 \mathrm{~A}$.
} 
canceladas à intuição e as próprias imagens como formas teóricas ao tempo que seu conteúdo permanece transformado em sua própria singularidade no conteúdo já ideal, não-figurativo, da representação do significado. ${ }^{16} \mathrm{Com}$ isto, o objeto singular do mundo externos existe agora como um modo de ser específico da subjetividade, com a forma da existência própria da mesma. Em efeito, um indivíduo particular, por exemplo, Júlio César ou Napoleão, desaparece em sua concreção sensível no ato mesmo em que é o bem simbolizado - por exemplo, mediante a figura de uma coroa de laurea - ou designado por uma determinada sequência de sons ou traços de tinta - a saber, a de seu nome; o conteúdo singular mesmo, sem dúvida até esse momento um conteúdo sensível, a saber: Júlio César ou Napoleão em pessoa, perdura ante o sujeito assimilado e homogeneizado agora a sua idealidade constitutiva como o conteúdo não-sensível da representação de um significado. ${ }^{17}$ No ato de simbolização e designação, pois, o sujeito humano suprime a primigênia correlação da determinação lógica da singularidade com as formas teóricas da intuição e a imagem.

Desta feita o significado de um signo é como tal um conteúdo ou bem singular ou bem universal. Sem dúvida desde o momento que implica o conteúdo singular da intuição, o conteúdo da representação do significado permanece no signo posto como uma unidade de singularidade e universalidade. A explicitação desta unidade transforma o mero signo em um signo propriamente linguístico, isto é, numa palavra (Wort) ou nome (Name). O efetivo desdobramento da unidade que as palavras ou nomes contém não é para Hegel senão o discurso (Rede) e, ulteriormente, seu sistema, a saber, a linguagem (Sprache). ${ }^{18}$

Quando um signo torna-se a unidade elementar de uma linguagem, o conteúdo da representação que funciona como seu significado é posto como uma conteúdo tanto universal como singular, ou, mais precisamente, como um conteúdo que pode ser em si mesmo tanto universalizado como singularizado. Com efeito, a passagem da presença singular do conteúdo a sua presença universal - ou o inverso - acontece na linguagem sem que o sujeito necessite separar-se para isso do conteúdo da representação do significado, a saber, acontece no interior mesmo de dito conteúdo, como um movimento interno de sua própria identidade específica.

\footnotetext{
${ }^{16}$ Cf. Hegel, G. W. F., Nürnberger und Heidelberger Schriften (1808-1817) (Hegel: Werke 4). Frankfurt am Main: Surkamp Verlag, 1970, § 159; Enz § 462A; VPhG, 215; 218-219.

${ }^{17} \mathrm{VPhG}, 215$.

${ }^{18}$ Cf. Enz $§ 459$.
} 
O retorno ao objeto singular do mundo real prescinde na linguagem, pois, das formas teóricas correlacionadas ao princípio do processo cognitivo com a singularidade e a objetividade, a saber, prescinde da intuição e, ulteriormente, da imagem, porém também a universalização linguística prescinde da forma teórica correlacionada primariamente com a universalidade, a saber, prescinde da representação abstrata, a qual exclui de si o indivíduo e exige por isso mesmo que este se lhe apresente ao sujeito numa intuição ou numa imagem sensível. ${ }^{19}$

A linguagem supera, pois a contraposição entre a mente humana e o mundo, o caráter particular de sua diferença e o faz justamente porque contém em si mesmo - ou pode conter - esse mundo. A presença real e concreta do mundo sob uma intuição simplesmente repetiria o que a linguagem já formulou ou pode formular. Mediante a descrição linguística de um fato singular concreto torna-se superflua uma intuição sensível do mesmo; se a proposição que o descreve é verdadeira, a intuição sensível não agregaria mais que o que já tenha sido dito pela linguagem ou que a linguagem está em condições de dizer. Com isto, o mundo real - o qual pode eventualmente voltar a apresentar-se ao sujeito sob a forma da intuição - certamente não desaparece; sem dúvida sua relação com o sujeito não tem já mais a figura de uma contraposição. Neste ponto preciso e onde na teoria do conhecimento de Hegel a forma da imaginação se supera numa nova forma cognitiva especificamente nova e diferente, a saber: o pensar ou compreender como unidade da intuição e a representação, da singularidade e a universidade, da sensibilidade e a inteligibilidade. ${ }^{20}$

\section{Imaginação, compreensão e verdade}

A imaginaçao tem sido concebida ao largo da história da filosofia como o ponto de encontro entre duas esferas gnoseológicas - e, eventualmente, sobre esta base, entre duas esferas ontológicas - especificamente diferentes, a saber: a dos objetos sensíveis e a dos objetos inteligíveis. A novidade da teoria hegeliana da imaginação radica antes de tudo na identidade que lhe atribui o conteúdo dessas duas esferas. Com efeito, para

\footnotetext{
19 Veja-se a este respeito Ferreiro, H. (2010). La relación entre lenguaje y pensamiento en el Sistema hegeliano. En Oliva Mendoza, C. (Ed.), Hegel: Ciencia, experiencia y Fenomenología (pp. 21-33). México: Ediciones de la Facultad de Filosofía y Letras de la Universidad Nacional Autónoma de México. ${ }^{20}$ A forma teórico da memória (Gedächtnis) tem neste contexto tão somente a função de idealizar numa unidade os dois elementos que compõe as palabras ou nomes, a saber, o ignificado e o conteúdo que o designa.
} 
Hegel a imagem e o conceito abstrato partilham um e o mesmo conteúdo específico ou determinidade; sua diferença esta dada tão somente pela forma na qual a mente humana a concebe em cada caso: sensibilidade e inteligibilidade derivam, mais precisamente do grau de contextualização de cada conteúdo de conhecimento com referência aos demais conteúdos conhecidos pelo sujeito. O ponto no qual sensibilidade e inteligibilidade se vinculam e superam numa unidade não é para Hegel a atividade da imaginação, dado que ela é somente um tertium medium que sintetiza aquelas formas de maneira extrínseca como se trata-se de dois conteúdos diferentes, senão a compreensão de sua única determinidade em relação a qual os caracteres sensíveis e inteligíveis tornam-se simples modos de apresentação da mesma. A imaginação assinala assim uma fase intermediária na elevação da inteligência ao plano próprio de cada determinidade como tal. A imaginação é para Hegel, em efeito, o meio no qual as duas versões da determinidade respectiva dos objetos que conhece, isto é, a versão concreta ou sensível e a versão menos concreta ou inteligível, se diferenciam e relacionam desde essa diferença. A imaginação realiza com isto de modo eminencial a essência da forma teórica da representação: os diversos atos da imaginação consistem precisamente em que neles o sujeito se apresenta a si mesmo um conteúdo frente a outro conteúdo, que, ainda que é diferente, é, sem dúvida o mesmo, ${ }^{21}$ razão pela qual a subjetividade se constitui em tais atos no âmbito formal da representação deste último conteúdo, que por sua vez permanece constituído frente ao conteúdo subjetivo numa coisa de um mundo externo. O processo de constituição da determinidade respectiva dos objetos do conhecimento mediante atos de diferenciação e re-identificação posterior é o que para Hegel define como tal a atividade de conhecer. A imaginação segundo se expôs, assinala o ponto médio desse processo de constituição, isto é, mais precisamente o estágio no qual a mente humana dissocia o objeto inicialmente dado como um bloqueio quase-indeterminado como se trata-se de dois conteúdos diferentes - o conteúdo-coisa do mundo externo e o conteúdo interno da própria mente - e de onde então ambas as versões do objeto devem corroborar-se mutuamente ao modo de uma síntese de elementos heterogêneos que somente em seu cotejamento mesmo reconhecem a sua

21 Se o conhecimento do sujeito é conhecimento do real deve tratar-se então de uma e a mesma determinidade em ambos os conteúdos. 
identidade. Esta síntese particular que realiza a imaginação é, desde outra perspectiva, a da verdade entendida como uma correspondência. ${ }^{22}$

Uma vez compreendido o objeto do conhecimento, seus caracteres sensíveis inicialmente externos e seus caracteres inteligíveis inicialmente internos se integram como aspectos inteiramente idealizados de sua única determinidade e superam com isso sua anterior diferença e particularidade. Na medida em que acontece de modo imediato através da linguagem e no elemento da linguagem, a atividade de compreensão pode ser caracterizada em certo sentido como um acontecimento interior e não-sensível; sem dúvida a compreensão não exclui para Hegel a eventual sensibilidade do objeto singular linguisticamente compreendido. Com efeito, este permanece em sua totalidade permeável a sensibilidade, já que não somente pode retornar sempre ao sensível, senão que de fato o faz continuamente: não se pode estar consciente sem estar ao mesmo tempo, forçosamente, tendo sensações e compreendendo os seus conteúdos. Deste modo, no pensar que compreende não desaparece a intuição nem a singularidade: por sua vez, a determinidade compreendida não é como tal um conteúdo abstratamente universal ou inteligível, fora do qual e frente ao qual se encontra a síntese dos objetos da imaginação, os objetos compreendidos contêm em si mesmo os aspectos sensíveis singulares como superados e mediados na universalidade inteligível.

A tradição empirista tendeu a conceber o inteligível, em contraposição ao sensível, como um produto imanente e espontâneo do espírito humano e não, tal como o fizeram, por exemplo, Platão e Aristóteles e seus epígonos medievais, como um conteúdo também recebido desde o mundo externo via causal. De acordo com a leitura que Hegel faz da história da filosofia, com Descartes a noção de espontaneidade se estende e abarca assim o sensível: nem o sensível, nem o inteligível seriam, segundo isto, conteúdos causados e recebidos.

Assim, uma espontaneidade em ambos os polos parece deixar caminho aberto a criatividade pura da subjetividade: o problema que se coloca com isso é, mais

\footnotetext{
${ }^{22}$ Hegel denomina a verdade por correspondência "correção" (Richtigkeit) e também - ainda que com menor frequência - "verdade formal" - (formelle Wahrheit). Ver Enz § 213Z: Unter Wahrheit versteht man zunächst, daß ich wisse, wie etwas ist. Dies ist jedoch die Wahrheit nur in Beziehung auf das Bewußtsein oder die formelle Wahrheit, die bloße Richtigkeit. Dahingegen besteht die Wahrheit im tieferen Sinn darin, daß die Objektivität mit dem Begriff identisch ist. Cf. también Enz § 33, Enz § 24Z.1; Enz § 172Z; Enz § 444Z; asimismo Hegel, G. W. F., Wissenschaft der Logik (Hegel: Werke 5). Frankfurt am Main: Surkamp Verlag, 1970, 29; Wissenschaft der Logik (Hegel: Werke 6), 497 y 519; Hegel. G.W.F., Grundlinien der Philosophie des Rechts (Hegel: Werke 7). Frankfurt am Main: Surkamp Verlag, $1970, \S 2 \mathrm{Z}$.
} 
claramente, como conciliar a espontaneidade total do conhecer, a saber, a espontaneidade de todo o ato de conhecimento - tanto dos conteúdos inteligíveis como dos sensíveis - com a eventual objetividade e a própria verdade do mesmo. Pareceria assim, se é que a mente humana quer evitar o perigo de girar se fricção no vazio que no conhecimento é necessário a pesar de tudo um lugar para a receptividade, a saber, nas palavras de John McDowell, que é necessário conservar um empirismo mínimo ${ }^{23}$; pareceria, com efeito, que somente conservando o caráter receptivo das sensações resulta possível atingir a "fricção" capaz de constituição o contexto normativo pelo qual no fenômeno de conhecer se trata propriamente de conhecer em forma correta ou verdadeira a realidade. Para Hegel, sem dúvida, a exigência de um controle externo como único meio de legitimar o conhecimento é uma pseudo-exigência da subjetividade quando não pode conceber o fenômeno do conhecer mais que em termos de representação e correspondência, a saber, para expressá-lo de outro modo, em termos de modelo e cópia, de causa e efeito. Desde as premissas da filosofia de Hegel o que opera em tal caso como o ponto cego de análise das condições de conhecimento é, em efeito, uma teoria representacionalista, correspondista e causalista do mesmo, teoria própria do estágio geral da consciência (Bewusstsein). Pelo contrário, para poder entender a especificidade da teoria hegeliana do conhecimento - e com isso, o sentido e função específicos da imaginação dentro da mesma - é necessário entender a mudança de paradigma que Hegel propõe com sua particular concepção da atividade de compreensão da identificação do sujeito e do objeto e, nessa medida, como superação do dualismo da consciência. Segundo este novo paradigma, o conhecer não consiste atos subjetivos de representação do mundo externo, como se a mente humana fosse uma sorte de espelho que reflete o real, senão que a subjetividade contém em si mesma o mundo na exata medida em que conhecer é precisamente enquanto tal a unidade desse como ato subjetivo e da realidade como seu objeto. Em efeito, o conhecimento não é para Hegel o ato de um sujeito pelo qual o mesmo se relaciona com outra coisa que de imediato neste ato torna-se seu objeto, não é o vínculo entre o sujeito e o objeto como duas substâncias diferentes que devem então conectar-se através do conhecer entendido

\footnotetext{
${ }^{23}$ McDowell, J. (1994). Mind and World. Cambridge: Harvard University Press, 11, 67 et passim. Cf. também McDowell, J. (1994). The Content of Perceptual Experience. Philosophical Quarterly, 15, 190205; ídem (1999). Scheme-Content Dualism and Empiricism. En Hahn, L. (Ed.), The Philosophy of Donald Davidson (pp. 87-104). Chicago and Lasalle: Open Court; ídem (2003). Hegel and the Myth of the Given. En Welsch, W., Vieweg, K. (Eds.), Das Interesse des Denkens. Hegel aus heutiger Sicht (pp. 75-88), München: Wilhelm Fink Verlag. Véase asimismo Houlgate, S. (2006). Thought and Experience in Hegel and McDowell. European Journal of Philosophy. 14 (2), 242-261.
} 
como um instrumento (Werkzeug) ${ }^{24}$ : para Hegel o conhecimento é já ele mesmo, como tal, a relação e a unidade do sujeito e do objeto, da mente e do mundo.

Assim se o conhecimento implica enquanto tal a unidade da mente e do mundo, o problema de sua objetividade e verdade, a rigor, não desaparece, senão que se coloca adiante desde o ângulo oposto, isto e, desde o de sua eventual falsidade: com feito, conceber, como o faz Hegel, a intrínseca intencionalidade da atividade de conhecer como a identidade já consumada do sujeito com a própria realidade - justamente por esta razão Hegel concebe o sujeito como a autêntica substância spinoziana - parece eliminar novamente a possibilidade de um critério normativo desde o qual resulte possível decidir em que condições um ato cognitivo é incorreto. Hegel nega expressamente que o conhecimento sensível tenha neste contexto um privilégio epistêmico: os conteúdos sensíveis ou perceptuais são para Hegel um momento além do objeto tanto como o são os conteúdos conceituais abstratos. Assim, o que na teoria do conhecimento contemporânea de rasgo analítico pode-se denominar por controle ou sujeição externa do conhecimento (external constraint) vem dado para Hegel pela coerência e sistematicidade mesmas da teoria geral do objeto ou conceito. É até o interior deste plexo lógico de onde aparece cada objeto singular, reunindo em si mesmo, intermediadas, determinações sensíveis e inteligíveis. O núcleo sistematizante de cada objeto - a coisa mesma (die Sache selbst) - começa a explicitar-se na forma geral da representação e, dentro desta, especialmente na da imaginação, porém nestas formas o faz todavia no meio refratário da reflexão (Reflexion): na imaginação, com efeito, sujeito e objeto aparecem enfrentados cada um em sua própria autonomia frente ao outro. Na medida em que não se tem mediados ainda completamente um com o outro no sistema da compreensão, tanto o objeto como o sujeito se apresentam como reciprocamente livres e arbitrários: o objeto sensível se comporta ante o sujeito segundo sua própria lei e o sujeito que imagina, associa e fantasia também o faz segundo sua própria vontade e gosto. A diverso do que ocorre na imaginação, na compreensão os dois polos do conhecimento se medeiam um com outro e superam sua arbitrariedade e particularidade num sistema que é necessário como livre, posto que não há nada externo a ele que o coacione e o controle. Chegada a sua forma final, a atividade do conhecimento põe de manifesto que o critério de justificação de seus conteúdos é inteiramente imanente; a norma de sua verdade não é outra coisa que a necessidade

${ }^{24}$ Cf. Hegel, G. W. F., Phänomenologie des Geistes (Hegel: Werke 3). Frankfurt am Main: Surkamp Verlag, 1970, 68-69. 
interior que rege a integração de cada determinação conhecida no sistema total de silogismos que define como tal a compreensão.

\section{Bibliografía}

Banham, G. (2005). Kant's Transcendental Imagination. New York: Palgrave Macmillan.

Bates, J. A. (2004). Hegel's Theory of Imagination. Albany: State University of New York Press.

Bundy, M. W. (1928). The Theory of Imagination in Classical and Medieval Thought, Urbana: University of Illinois Press.

Düsing, K. (1991). Hegels Theorie der Einbildungskraft. In Hespe, F., Tuschling, B. (Eds.), Psychologie und Anthropologie oder Philosophie des Geistes. Beiträge zu einer Hegel-Tagung in Marburg 1989 (pp. 297-320). Stuttgart-Bad Canstatt: Frommann-Holzboog.

Engmann, J. (1976). Imagination and Truth in Aristotle. Journal of the History of Philosophy, 14 (3), 259-265.

Ferrarin, A. (1995). Construction and Mathematical Schematism: Kant on the Exhibition of a Concept in Intuition. Kant-Studien, 86 (2), 1-47.

(1995). Kant's Productive Imagination And Its Alleged Antecedents, Graduate Faculty Philosophy Journal, 18 (1), 65-92.

Ferreiro, H. (2010). La relación entre lenguaje y pensamiento en el Sistema hegeliano. En Oliva Mendoza, C. (Ed.), Hegel: Ciencia, experiencia y Fenomenología (pp. 21-33). México: Ediciones de la Facultad de Filosofía y Letras de la Universidad Nacional Autónoma de México.

------. (2012). La interpretación hegeliana del Cogito. En Lorenzo, L., Paul, A. (Eds.), Perspectivas de investigación en Filosofía: Aporías de la razón moderna (pp. 41-52). Los Polvorines-Buenos Aires: Ediciones de la Universidad Nacional de General Sarmiento.

Freydberg, B. (2005). Imagination in Kant's Critique of Practical Reason. Bloomington and Indianapolis: Indiana University Press.

Hegel, G. W. F., Phänomenologie des Geistes (Hegel: Werke 3). Frankfurt am Main: Surkamp Verlag, 1970.

-. Nürnberger und Heidelberger Schriften (1808-1817) (Hegel: Werke 4). Frankfurt am Main: Surkamp Verlag, 1970. 
- Wissenschaft der Logik (Hegel: Werke 5-6). Frankfurt am Main: Surkamp Verlag, 1970.

. Grundlinien der Philosophie des Rechts (Hegel: Werke 7). Frankfurt am Main: Surkamp Verlag, 1970.

-. Enzyklopädie der philosophischen Wissenschaften im Grundrisse (Hegel: Werke 8-10). Frankfurt am Main: Surkamp Verlag, 1970.

----------. Vorlesungen über die Geschichte der Philosophie (Hegel: Werke 18-20.) Frankfurt am Main: Surkamp Verlag, 1970.

---------. Vorlesungen über die Philosophie des Geistes. Berlin 1827/1828. Nachgeschrieben von J E. Erdmann und F. Walter, Hamburg: Meiner, 1994.

Houlgate, S. (2006). Thought and Experience in Hegel and McDowell. European Journal of Philosophy. 14 (2), 242-261.

Kemp, S. (1996). Cognitive Psychology in the Middle Ages. Westport: Greenwood Press.

Kemp, S., Fletcher, G. (1993). The Medieval Theory of the Inner Senses, American Journal of Psychology, 106, 559-576.

Labarrière, J.-L. (1984). Imagination humaine et imagination animale chez Aristote. Phronesis, 29, 17-49.

Lachterman, D. (1989). The Ethics of Geometry: A Genealogy of Modernity. New York: Routledge.

Makkreel, R. (1990). Imagination and Interpretation in Kant. Chicago: The University of Chicago Press.

Marion, J.-L. (1975). Sur l’ontologie grise de Descartes. Paris: Vrin.

McDowell, J. (1994). Mind and World. Cambridge: Harvard University Press. -. (1994). The Content of Perceptual Experience. Philosophical Quarterly, 15, 190-205.

-. (1999). Scheme-Content Dualism and Empiricism. En Hahn, L. (Ed.), The Philosophy of Donald Davidson (pp. 87-104). Chicago and Lasalle: Open Court.

(2003). Hegel and the Myth of the Given. En Welsch, W., Vieweg, K. (Eds.), Das Interesse des Denkens. Hegel aus heutiger Sicht (pp. 75-88), München: Wilhelm Fink Verlag.

Modrak, D. (1986). Phantasia reconsidered. Archiv für Geschichte der Philosophie, 68, 47-69.

Rees, D. (1971). Aristotle's Treatment of Phantasia. En Anton, J., Kustas, G. (Eds.), Essays in Ancient Greek Philosophy (pp. 491-504). Albany: State University of New York Press. 
Sallis, J. (1987). Spacings - of Reason and Imagination in Texts of Kant, Fichte, Hegel. Chicago/London: The University of Chicago Press.

--------. Imagination and Presentation in Hegel's Philosphy of Spirit. En Stillman, P. (Ed.), Hegel's Philosophy of Spirit (pp. 66-88). Albany: State University of New York Press;.

Schofield, M. (1978). Aristotle on the Imagination. En Lloyd, G., Owen, G. (Eds.), Aristotle on Mind and the Senses (pp. 99-141). Cambridge: Cambridge University Press.

Tomás de Aquino, Summa Theologiae, ed. Busa, Stuttgart-Bad Cannstatt: FrommannHolzboog, 1980.

In IV libros Sententiarum, ed. Busa, Stuttgart-Bad Cannstatt: FrommannHolzboog, 1980.

Verene, D. (1982). La imaginación en Hegel. Revista de Filosofía, 20, 23-35.

Watson, G. (1982). Phantasia in Aristotle: De Anima 3.3., Classical Quarterly, 32, 101113.

(1988). Phantasia in Classical Thought, Galway: Galway University Press.

Wedin, M. (1988). Mind and Imagination in Aristotle, New Haven: Yale University Press.

White, K. (1985). The Meaning of Phantasia in Aristotle's De Anima, III, 3-8, Dialogue, 24, 483-505. 